\title{
Controls on surface soil drying rates observed by SMAP and simulated by the Noah land surface model
}

\author{
Peter J. Shellito ${ }^{1}$, Eric E. Small ${ }^{1}$, and Ben Livneh ${ }^{2}$ \\ ${ }^{1}$ Geological Sciences, University of Colorado Boulder, Boulder, 80309, USA \\ ${ }^{2}$ Cooperative Institute for Research in Environmental Science, and Department of Civil, Environmental, \\ and Architectural Engineering, University of Colorado Boulder, Boulder, 80309, USA
}

Correspondence: Peter J. Shellito (shellito@gmail.com)

Received: 14 June 2017 - Discussion started: 27 July 2017

Revised: 5 January 2018 - Accepted: 26 January 2018 - Published: 6 March 2018

\begin{abstract}
Drydown periods that follow precipitation events provide an opportunity to assess controls on soil evaporation on a continental scale. We use SMAP (Soil Moisture Active Passive) observations and Noah simulations from drydown periods to quantify the role of soil moisture, potential evaporation, vegetation cover, and soil texture on soil drying rates. Rates are determined using finite differences over intervals of 1 to 3 days. In the Noah model, the drying rates are a good approximation of direct soil evaporation rates, and our work suggests that SMAP-observed drying is also predominantly affected by direct soil evaporation. Data cover the domain of the North American Land Data Assimilation System Phase 2 and span the first 1.8 years of SMAP's operation.

Drying of surface soil moisture observed by SMAP is faster than that simulated by Noah. SMAP drying is fastest when surface soil moisture levels are high, potential evaporation is high, and when vegetation cover is low. Soil texture plays a minor role in SMAP drying rates. Noah simulations show similar responses to soil moisture and potential evaporation, but vegetation has a minimal effect and soil texture has a much larger effect compared to SMAP. When drying rates are normalized by potential evaporation, SMAP observations and Noah simulations both show that increases in vegetation cover lead to decreases in evaporative efficiency from the surface soil. However, the magnitude of this effect simulated by Noah is much weaker than that determined from SMAP observations.
\end{abstract}

\section{Introduction}

Though the volume of water is small, surface soil moisture generates outsized effects on the global water and energy balance (McColl et al., 2017b). Climate, weather, and flood predictions depend on soil moisture (Entekhabi et al., 1996; Viterbo and Betts, 1999). Feedback between the land and atmosphere can perpetuate soil moisture anomalies differently depending on the climatic regime (Koster et al., 2004; Tuttle and Salvucci, 2016). The duration of soil moisture anomalies depends on the drying rate of soil, which is controlled by complex interactions between soil hydrologic processes, atmospheric conditions, and vegetation state (e.g., RodriguezIturbe, 2000). Therefore, documenting the controls on soil drying is necessary to more fully understand the role of terrestrial hydrologic processes and land-atmosphere interactions in the climate system. In this study, we use satellite data from NASA's SMAP (Soil Moisture Active Passive) mission and ancillary datasets to investigate such processes, specifically direct soil evaporation.

Soil moisture loss mechanisms include runoff, drainage, and evapotranspiration $\left(E_{\mathrm{T}}\right)$. The relative dominance of each depends on how much time has passed since rainfall (Laio et al., 2001). Runoff, when present, ceases only minutes after rainfall. Drainage occurs on a timescale of hours. Thus both can be ignored when considering drying intervals on a timescale of days, as is documented by the 1-3-day SMAP soil moisture observations (Chan et al., 2016). Assuming drainage is negligible outside of rainy intervals is a common assumption in models of soil moisture dynamics (Federer et al., 2003; Guswa et al., 2002; e.g., Laio et al., 2001; McColl et al., 2017a; Porporato et al., 2004). 
At the continental scales observed by SMAP, these assumptions result in a loss function dominated by stage two (water-limited) $E_{\mathrm{T}}$ (McColl et al., 2017a). Water-limited $E_{\mathrm{T}}$ is itself the sum of two fluxes: (1) direct evaporation from the soil surface, which typically occurs over a depth of several centimeters and (2) transpiration via plant stomata, which removes water from throughout the root zone (Campbell and Norman, 1998; Monteith and Unsworth, 2013). Given the shallow sensing depth of L-band radiometers (Njoku and Entekhabi, 1996), we expect SMAP to capture mainly the former. Accordingly, our study is framed around assessing the controls on direct evaporation on the continental scale. We include surface soil moisture, potential evaporation (PE) rate, vegetation, and soil texture in our assessment, as these quantities are all expected to control direct soil evaporation rates.

Surface moisture (volumetric soil moisture, VSM) supply is known to affect evaporation rates. In the Noah land surface model (LSM) and other models, moisture stress scales evaporation rates according to a piecewise function. Above field capacity, evaporation proceeds at its potential rate (stage one evaporation); below a residual soil moisture content, no evaporation occurs; between the two thresholds, evaporation depends on relative moisture content (Allen, 2000; Chen and Dudhia, 2001).

Atmospheric moisture demand is quantified by the PE rate and is also known to affect evaporation rates. Surface vapor pressure, atmospheric vapor pressure, radiation, albedo, and wind velocity contribute to its calculation (Mahrt and Ek, 1984; Penman, 1948).

Any vegetation present on the land surface introduces two counteracting effects on soil drying that do not exist for bare soil surfaces. Direct evaporation decreases because of shading from the canopy that intercepts solar radiation (Mahfouf and Noilhan, 1991). Transpiration draws moisture from the root zone into the atmosphere, with the depth of this flux depending on root distribution (Schenk and Jackson, 2002).

The soil texture of the land surface, and thus its hydraulic properties, also influences soil drying. Compared with finetextured soils (clay), coarser soils (sand) have more wellconnected pores, allowing water to leave the system more easily at a given moisture level (Campbell, 1974; Clapp and Hornberger, 1978; Cosby et al., 1984; Van Genuchten, 1980). These differences cause volumetric soil moisture to be lower for coarse textures than for fine (Laio et al., 2001). Despite the efforts that have gone into quantifying and modeling the effects of textural differences on soil moisture and heat fluxes, there remains much variability within each texture class, so assigning model parameter values based on continental-scale soil maps has proven to be problematic (Gutmann and Small, 2005; Xia et al., 2015b). Nevertheless, the Noah LSM and other models use soil texture to assign soil hydraulic properties, which dictate the infiltration and redistribution of moisture in the soil column (Chen and Dudhia, 2001).
Studying evaporation and its contribution to total $E_{\mathrm{T}}$ is necessary to more completely understand and model the flux of water from the land surface to the atmosphere (Kool et al., 2014). However, continental-scale evaporation from soil is notoriously difficult to measure directly. Lysimeters and chamber measurements provide information over extremely small areas $\left(\sim 10 \mathrm{~m}^{2}\right.$ or less) (e.g., Herbst et al., 1996; Stannard and Weltz, 2006). Soil drying rates determined from satellite-based observations can provide an estimate of surface evaporation rates on a large scale (McColl et al., 2017a). This requires that the depth supplying evaporation is sampled by the sensor and that vertical redistribution within the soil is negligible. Evaporation largely draws from the top several centimeters of the soil column, within the sensing depth of L-band radiometers (Njoku and Entekhabi, 1996), although under extreme dry conditions the evaporative front will propagate down to greater depths. In addition, L-band sensing depth varies slightly with moisture content (Njoku and Kong, 1977), though quantifying the effect of this change is beyond the scope of this study.

In situ observations have allowed for investigation into how different environmental factors control soil drying rates and thus evaporation rates (Cavanaugh et al., 2011; Detto et al., 2006; e.g., Kurc and Small, 2004, 2007). Only recently has satellite remote sensing of soil moisture advanced sufficiently to make it possible to monitor drying rates on a large scale (Entekhabi et al., 2010; Kerr, 2006), thus allowing scientists to evaluate the physical controls on soil drying across a wider range of conditions. McColl et al. (2017a) studied global soil drying dynamics by fitting SMAP surface soil moisture observations to an exponential decay function. They found shorter drying timescales in areas that have higher aridity indexes and higher soil sand content, although the effects of soil texture were relatively minor. Their results confirm the expected roles of atmospheric demand and soil texture on soil drying, and thus presumably also on direct evaporation. They noted, however, that there was substantial unexplained variance in drying timescales, citing vegetation as a likely factor. In addition, McColl et al. (2017a) only considered static descriptors of the physical environment at each location: neither aridity index nor soil texture vary through time. Yet, the soil drying process represents a dynamic interplay between hydrologic, climatic, and ecosystem processes (Rodriguez-Iturbe, 2000).

Here, we do not fit an exponential decay model to drydown events as in McColl et al. (2017a). Instead we use calculations of changes in surface soil moisture through time, which Shellito et al. (2016b) showed to provide a similar depiction of soil drying as the exponential approach. Importantly, by analyzing simple soil drying rates we avoid introducing new uncertainties into our analysis associated with fitting an exponential decay model.

Our study builds upon McColl et al. (2017a) in two ways. First, we examine the effects of dynamic controls on soil drying, rather than static covariates. Soil moisture supply, PE 
rate, and vegetation cover are observed or calculated coincident with both the time and location of the SMAP drying observations. This approach allows us to obtain results indicative of time-varying hydrological mechanisms and processes, rather than of the overall climate (e.g., aridity index) or soil type in each location.

Second, we compare our results to output from the Noah LSM (Ek et al., 2003; Xia et al., 2012a). Noah development and validation have been more focused on reproducing heat fluxes and runoff than soil moisture (Chen and Dudhia, 2001; Xia et al., 2012a, b). A comparison between Noah and the North American Soil Moisture Database shows it is able to capture broad features of soil moisture variations (Xia et al., 2015a). Accurately simulating specific soil drydowns is more difficult. By analyzing Noah soil drying rates alongside the observations from SMAP, we can offer guidance into the strengths and limitations of Noah-simulated soil moisture dynamics. In addition, the model helps guide and confirm our understanding of the relationship between surface drying rates and surface evaporation rates.

\section{Data and methods}

\subsection{Data}

Our study utilizes SMAP, North American Land Data Assimilation System phase 2 (NLDAS-2), and normalized difference vegetation index (NDVI) data from the nearly 2-year period since SMAP began operation: 31 March 2015 through 27 January 2017.

Although SMAP and NDVI data are available globally, the one-eighth degree NLDAS-2 forcing and simulation data cover only North America. Therefore, our study is limited to the continental land mass found between longitudes $124.9^{\circ}$ and $67.1^{\circ} \mathrm{W}$ and latitudes $25.1^{\circ}$ and $52.9^{\circ} \mathrm{N}$ (Fig. 1).

\subsubsection{SMAP retrievals}

SMAP was launched in January 2015 and provides morning and evening (06:00 and 18:00 LT) estimates of VSM $\left(\mathrm{cm}^{3} \mathrm{~cm}^{-3}\right)$ globally every 1-3 days (Entekhabi et al., 2014). Retrievals estimate soil moisture based on passive microwave $(1.41 \mathrm{GHz})$ brightness temperature and reach a nominal sensing depth of $5 \mathrm{~cm}$ as described in Entekhabi et al. (2014). We use the "enhanced" level 3 soil moisture data product, Version 1, which is available from the National Snow and Ice Data Center (O'Neill et al., 2016). The SMAP radiometer has a native spatial resolution of $36 \mathrm{~km}$, but this product utilizes the Backus-Gilbert optimal interpolation algorithm to post soil moisture retrievals onto the $9 \mathrm{~km}$ Equal-Area Scalable Earth grid version 2 (EASE-2) (O'Neill et al., 2016). The enhanced resolution version reveals spatial features not apparent in the $36 \mathrm{~km}$ standard product and similarly meets the mission goal of $0.040 \mathrm{~cm}^{3} \mathrm{~cm}^{-3}$ unbiased root mean squared error (Chan et al., 2018). We use only morning overpasses because the SMAP algorithm assigns one temperature to both the soil and its overlying canopy, a condition that is best met in the morning hours (Entekhabi et al., 2014; Jackson et al., 2012). We exclude data that have been flagged for uncertain quality due to dense vegetation $\left(>5 \mathrm{~kg} \mathrm{~m}^{-2}\right)$, mountainous terrain ( $>3^{\circ}$ slope standard deviation), and $>5 \%$ of the sensing area comprising frozen ground, snow, ice, precipitation, or static water. These exclusions decrease the number of SMAP observations by $56.5 \%$, mostly because of vegetation in the eastern portion of North America. Figure 1a shows the number of SMAP observations used in this study, after removing flagged data. The domain consists of 136422 SMAP pixels. Un-flagged SMAP observations are found in $59 \%$ of the pixels, so these 79987 "active" SMAP pixels are the focus of our study.

\subsubsection{NLDAS-2 precipitation, PE, and soil texture}

We use precipitation and PE data from the NLDAS-2 primary forcing fields (Xia et al., 2012b). Precipitation is from the NCEP Climate Prediction Center's unified gauge-based precipitation, which has been adjusted for orographic effects (Daly et al., 1994). Other meteorological forcings are from the National Center for Environmental Prediction (NCEP) North American Regional Reanalysis (NARR), interpolated to the NLDAS-2 one-eighth degree grid and disaggregated to hourly frequency (Cosgrove et al., 2003). PE is calculated from those forcings using the modified Penman scheme of Mahrt and Ek (1984).

Within the United States, NLDAS-2 provides a gridded soil texture field derived from $1 \mathrm{~km}$ State Soil Geographic (STATSGO) data (Miller and White, 1998; Mitchell et al., 2004). Although there are 15 categories, some types (silt, sandy clay loam, sandy clay, silty clay, organic materials, water, and bedrock) individually occupy less than $3 \%$ of the domain. We therefore focus on the four most common textures: loam $(26.0 \%)$, silt loam (25.9\%), sandy loam (23.0\%), and sand $(6.8 \%)$.

\subsubsection{Vegetation data}

NASA's Terra and Aqua satellites carry the MODIS instrument and provide NDVI data every 16 days globally, at a resolution of $1 \mathrm{~km}$. NDVI is linearly interpolated in the days between retrievals and upscaled to match the SMAP grid by taking the arithmetic mean of the MODIS cells contained in each SMAP pixel.

\subsubsection{NLDAS-2 Noah simulations}

As part of the NLDAS-2 project, Noah LSM simulations are run from 1979 to present and archived at the Goddard Earth Sciences Data and Information Services Center (GES DISC) (Xia et al., 2012b). Our study utilizes surface evaporation rates and surface soil moisture from these simulations. The top soil layer in the Noah LSM is $0-10 \mathrm{~cm}$, twice the ap- 

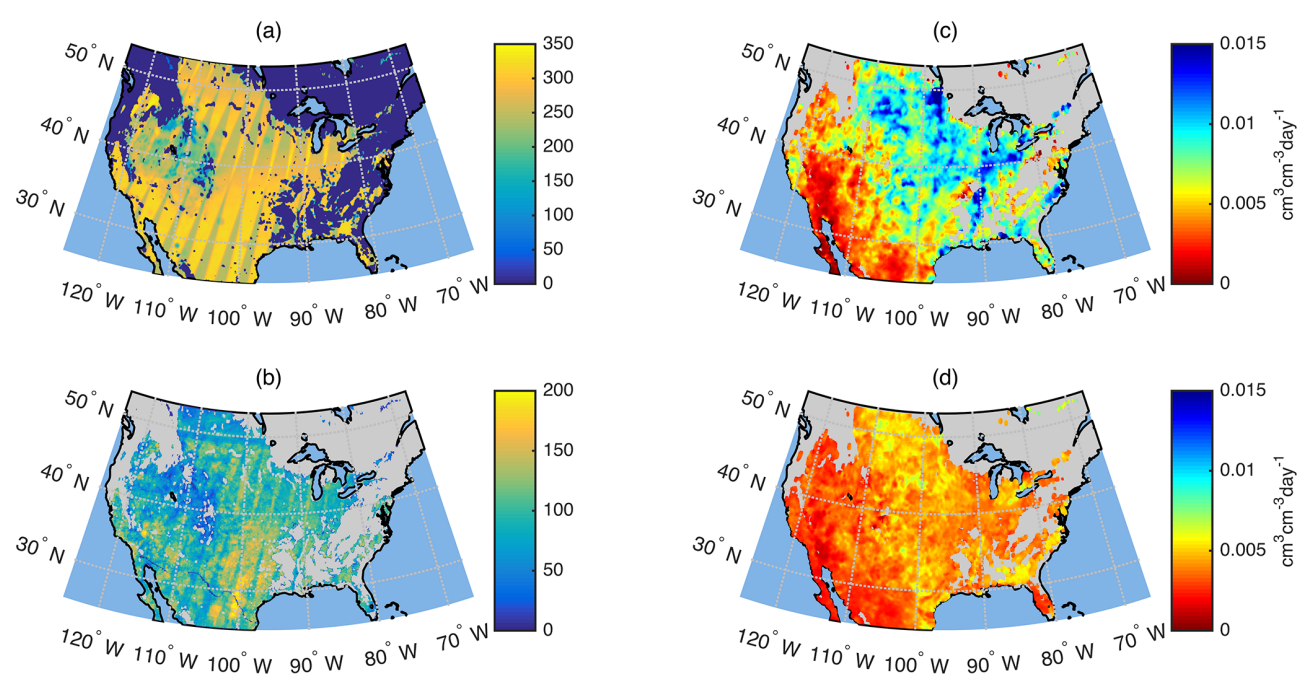

Figure 1. (a) Number of SMAP observations used in this study. (b) Number of drying rates calculated from SMAP observations and Noah simulations. (c) Median of SMAP drying rates. (d) Median of Noah drying rates. Drying rates are expressed as changes in volume per day $\left(\mathrm{cm}^{3} \mathrm{~cm}^{-3}\right.$ day $\left.^{-1}\right)$. Note that artifacts of SMAP's orbital track are visible in (a) and (b).

proximate sensing depth of SMAP. Soil moisture values are converted from $\mathrm{kg} \mathrm{m}^{-2}$ to $\mathrm{cm}^{3} \mathrm{~cm}^{-3}$ to be consistent with SMAP units.

Noah partitions evapotranspiration between surface evaporation and transpiration through a parameterization of the fraction of land that has green vegetation $\left(F_{G}\right)$ (Chen and Dudhia, 2001). This parameter is defined over a $1^{\circ}$ grid by Gutman and Ignatov (1998) using 5 years of NDVI data according to Eq. (1):

$F_{\mathrm{G}}=\frac{\mathrm{NDVI}-\mathrm{NDVI}_{0}}{\mathrm{NDVI}_{\infty}-\mathrm{NDVI}_{0}}$,

where $\mathrm{NDVI}_{0}$ is over bare soil and $\mathrm{NDVI}_{\infty}$ is over dense vegetation. Thus, Noah simulations use vegetation climatology at each point, not vegetation observations. In contrast, our analyses are based on NDVI observations themselves (Sect. 2.1.3). To understand how this difference might affect the Noah results presented here, we additionally look at the $F_{G}$ values in our study domain, which are provided as part of the NLDAS-2 Noah simulation dataset.

\subsubsection{Supplementary simulations}

SMAP and Noah do not represent identical soil depths. In addition to Noah simulations from NLDAS-2, we run the most recent Noah version (3.4.1) in two configurations for six US locations: Fort Cobb, OK; Little River, GA; Little Washita, OK; Marena, OK; St. Joseph's, IN; and Walnut Gulch, AZ. One simulation uses the default $0-10 \mathrm{~cm}$ layer one depth. The other uses a modified $0-5 \mathrm{~cm}$ layer one depth. In the latter case, layer two has been increased by $5 \mathrm{~cm}$ (to $5-40 \mathrm{~cm}$ ) to keep total model soil depth unchanged. Further information regarding the location, soil type, and vegetation cover in these locations can be found in Shellito et al. (2016a). The forcing data and parameter values for these simulations are taken from the NLDAS-2 data corresponding to each location. With these supplementary simulations, we can assess how Noah model soil moisture dynamics would change if its first layer depth were $0-5 \mathrm{~cm}$, instead of $0-10 \mathrm{~cm}$.

\subsection{Methods}

\subsubsection{Pixel matchups}

Our analyses require matching simulated or observed drying rates with concurrent observations of $\mathrm{PE}$, vegetation, and soil type. These datasets come from different sources (NLDAS2 and MODIS) and therefore have been re-gridded onto the SMAP EASE-2 grid.

MODIS grid cells, which are finer than SMAP's grid, have been averaged together within each SMAP pixel. The NLDAS-2 grid is only slightly coarser than SMAP's grid, so occasionally the same data will be mapped into two SMAP pixels. Though this is not ideal, it is preferable to basing our analysis on the NLDAS-2 grid, which would force us to exclude some SMAP pixels or blend them with their neighbor when they fall within the same NLDAS-2 pixel.

\subsubsection{Drydown periods}

We utilize the precipitation field in the NLDAS-2 forcing dataset to select drydowns for our analysis. Following Shellito et al. (2016b), a drydown is defined by a dry period that follows a soil wetting event. We automate this selection process for all pixels according to the following logic: (1) the event precipitation depth must surpass $5 \mathrm{~mm}$ in a $24 \mathrm{~h}$ period; (2) the dry period must begin after the event precipitation stops and end a day before $2 \mathrm{~mm}$ or more additional 
precipitation accumulates; and (3) the dry period must be at least 3 days long (Fig. 2). We note this differs from McColl et al. (2017a) that based the identification of dry down periods on the soil moisture time series alone and did not use any precipitation data. Results are insensitive to minor changes in the drydown selection criteria.

\subsubsection{Calculation of drying rates}

With both SMAP and Noah soil moisture data, we calculate soil drying rates contained within the drydown periods. As in Shellito et al. (2016b) we use a simple finite differences approach:

$$
\frac{\mathrm{d} \theta}{\mathrm{d} t}=\frac{\theta_{n+1}-\theta_{n}}{t_{n+1}-t_{n}} .
$$

$\theta$ is surface soil moisture content $\left(\mathrm{cm}^{3} \mathrm{~cm}^{-3}\right), t$ is time (days), and $\mathrm{n}$ and $n+1$ correspond to consecutive observations (Fig. 3). SMAP data are available every 1-3 days, so drying rates span at least $24 \mathrm{~h}$. Although simulated data are available hourly, we only use Noah soil moisture values that are concurrent with SMAP observations. This ensures that sampling frequency will not affect our comparison to Noah.

Our analysis produces 4738702 drying rates for both SMAP and Noah, or an average of 75.2 per active SMAP pixel (Fig. 1b). Figure 2 shows two representative soil moisture time series, the drydown periods contained therein, and the associated drying rates that have been calculated.

Preliminary analyses showed that SMAP observations can occasionally reach and stay at a maximum value, producing drying rates of exactly $0 \mathrm{~mm} \mathrm{day}^{-1}$. This is a feature of the SMAP algorithm, indicative of having reached its upper limit, and does not reflect the drying process (Andreas Colliander, personal communication, 2017). Cases where VSM stays constant at saturation during identified drydowns have been excluded.

The units of drying as calculated from SMAP surface soil moisture are $\mathrm{cm}^{3} \mathrm{~cm}^{-3} \mathrm{day}^{-1}$, a measure of the change in moisture volume through time. We express soil drying in two other ways. First, it is also useful to express drying rate in terms of the depth of water lost from the surface, to match the units of potential and actual evaporation. To convert from $\mathrm{cm}^{3} \mathrm{~cm}^{-3} \mathrm{day}^{-1}$ (volumetric change per day) to $\mathrm{mm}$ day $^{-1}$, we multiply SMAP-observed drying rates by SMAP's nominal sensing depth $(50 \mathrm{~mm}$, Entekhabi et al., 2014), and Noah-simulated drying rates by Noah's first layer thickness $(100 \mathrm{~mm})$. Second, we convert the drying rate to an evaporative efficiency: the fraction of PE that is realized by the above-calculated water loss.

The surface soil drying rate is a proxy for direct evaporation from the soil. Most vertical redistribution of precipitation occurs within hours of rainfall; thus these intervals are typically not captured by the SMAP overpass intervals used to calculate drying rates (Fig. 3). In the Noah LSM, $E_{\mathrm{T}}$ is partitioned between evaporation and transpiration, the former of which removes moisture only from the top model layer. In Fig. 4 we evaluate the correspondence of Noah evaporation with the drying rate calculated from the simulated soil moisture time series. The slope of the regression line is nearly $1(0.86)$. We therefore call the drying rate in $\mathrm{mm} \mathrm{day}^{-1}$ the "equivalent evaporation rate" of the land surface. Points lying above the $1: 1$ line indicate instances when transpiration and/or drainage are contributing to soil drying in addition to evaporation. The role of transpiration, however, is small because most plant types have $90 \%$ of their roots below $10 \mathrm{~cm}$ (Ek et al., 2003). In addition, Fig. 4 shows that the majority of points $(58.4 \%)$ lie below the $1: 1$ line, indicating that during most drydown periods, the magnitude of capillary rise is larger than drainage and transpiration combined. The equivalent evaporation rate is therefore a slightly conservative estimate (on average).

There is no equivalent way to test if SMAP drying rates also correspond to direct evaporation rates. However, it is reasonable to assume that the drying rates are similarly a proxy for direct evaporation. The equivalent evaporation rate of SMAP is based on a sensing depth that is half that of Noah's surface layer, so it will be a more conservative estimate than Noah's evaporation rate. There are fewer roots in this layer and thus less water loss from transpiration. In addition, any evaporation from below the $5 \mathrm{~cm}$ sensing depth is not accounted for. Because the evaporative efficiency is derived from the equivalent evaporation rate, this quantity will also be conservative, particularly for SMAP.

The evaporative efficiencies themselves are relatively low for both SMAP and Noah (Fig. 5). Ninety percent of the values are lower than 0.27 and 0.21 , respectively. SMAP even exhibits a considerable number of evaporative efficiency values below zero, indicating increases in soil moisture between consecutive overpasses. These negative evaporation efficiencies can be attributed to (1) the expected noise in SMAP observations (up to $0.04 \mathrm{~cm}^{3} \mathrm{~cm}^{-3}$ ), (2) the fact that soil drying rates trend towards zero in a given dry period (Figs. 2 and 3), thereby increasing the role of the aforementioned noise, and (3) small amounts of rainfall that are insufficient to trigger the end of a drydown period $(<2 \mathrm{~mm})$ but that cause real increases in soil moisture. Several instances of these negative evaporation rates can be seen in the upper panels of Fig. 2: late November at Fort Cobb, OK, and mid-October at Marena, OK.

We quantify the role of these three factors by flagging overpass intervals that (1) exhibit changes in soil moisture less than $0.04 \mathrm{~cm}^{3} \mathrm{~cm}^{-3}$, (2) include the driest $10 \%$ of SMAP observations (soil moisture values below $0.05 \mathrm{~cm}^{3} \mathrm{~cm}^{-3}$ ), and (3) have up to $2 \mathrm{~mm}$ precipitation. Overpass intervals that meet one or more of these conditions account for nearly all (98.5\%) of the negative evaporative efficiencies observed by SMAP. The remaining cases may be due to rainfall not included in the NLDAS forcing data.

We have chosen not to exclude the negative evaporative efficiency values from our analyses, as removing only a subset 

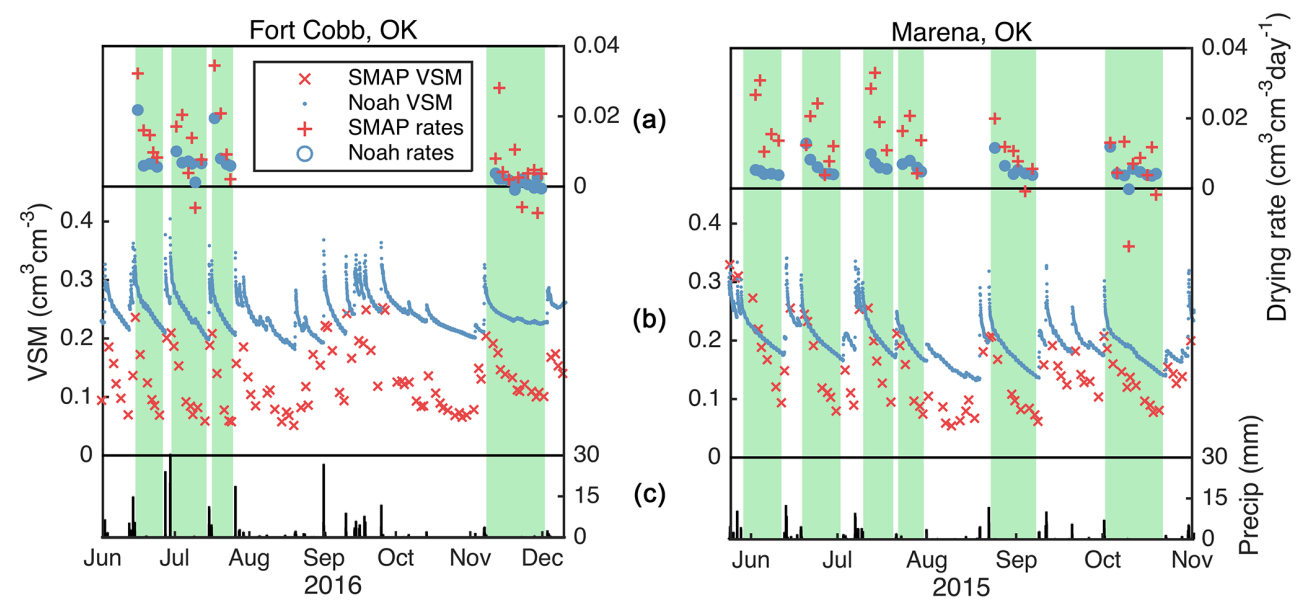

Figure 2. Precipitation (c), soil moisture (b), and drying rates (a) for two sites in Oklahoma: Fort Cobb $\left(98.573^{\circ} \mathrm{W}, 35.342^{\circ} \mathrm{E}\right)$ and $\mathrm{Marena}$ $\left(-97.217^{\circ} \mathrm{W}, 36.063^{\circ} \mathrm{E}\right)$. Drydowns are indicated with green shading.

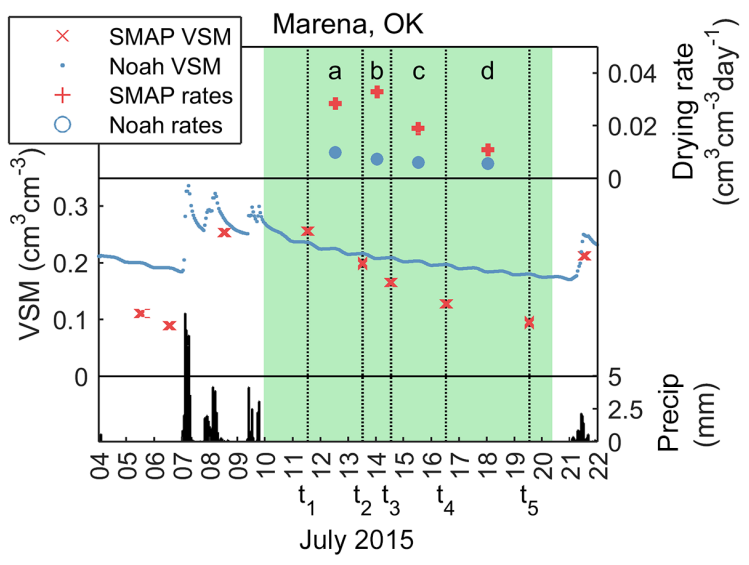

Figure 3. Detail from one drydown period. Drying rates a, b, c, and $\mathrm{d}$, are the changes in soil moisture divided by the width of each calculation interval, which is the time between consecutive SMAP overpasses. These are shown with dotted lines ( $t_{1}$ to $t_{2}, t_{2}$ to $t_{3}$, etc). Each drydown's PE and NDVI are taken as the average observed within the respective calculation intervals.

of noise from the full population would bias the results. Even with this noise included, clear relationships emerge when we compare median values to important variables (e.g., Fig. 7).

Alternative methods of analyzing drydowns, such as the exponential model used in McColl et al. (2017a) and Shellito et al. (2016b), must cope with the exact same noise in SMAP observations. In those cases, the noise just contributes to misfit in the exponential curve rather than negative evaporation values from individual observations. Shellito et al. (2016b) found nearly identical results using an exponential fit as finite differences, so our analyses are expected to be valid despite the noise inherent in SMAP observations.

Alternative methods of selecting drydowns, such as stricter drydown length requirements, are unrelated to the number of

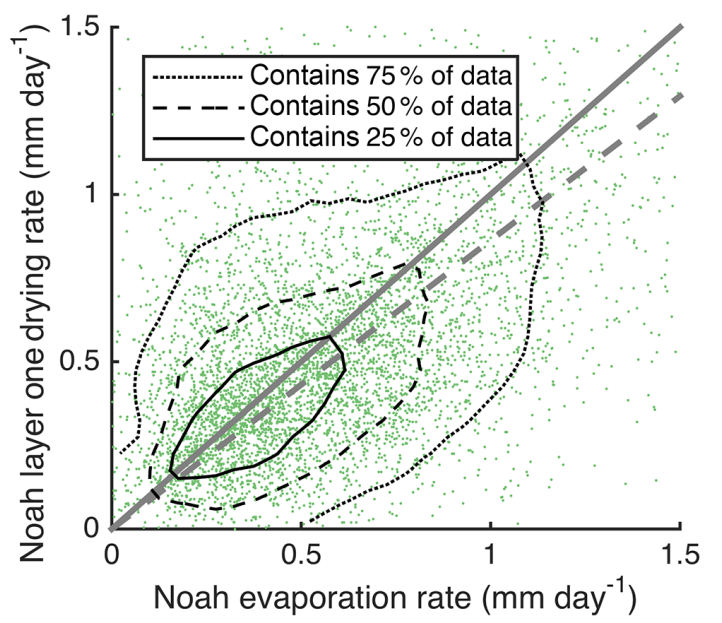

Figure 4. Scatter and contour plot showing correspondence of Noah layer one drying and evaporation rates. Displayed green markers show $0.1 \%$ of the $5+$ million data points. Contours are drawn using all data. The $1: 1$ line is shown in solid gray. The best fit line is shown in dashed gray. $R=0.47$.

noisy observations; only two observation go into each calculation, and SMAP overpasses occur every 1 to 3 days. Therefore, drydown periods of only 3 days are still useful and do not disproportionately contribute to noisy observations.

\subsubsection{Effects of meteorologic conditions and land surface states}

We quantify the roles of time since rainfall, surface moisture content, PE, vegetation, and soil texture on drying dynamics using the data described in Sect. 2.1. For each rate calculated (Eq. 2), we record the arithmetic mean of the associated meteorologic conditions and land surface states between $t_{n}$ and $t_{n+1}$ (Fig. 3). 


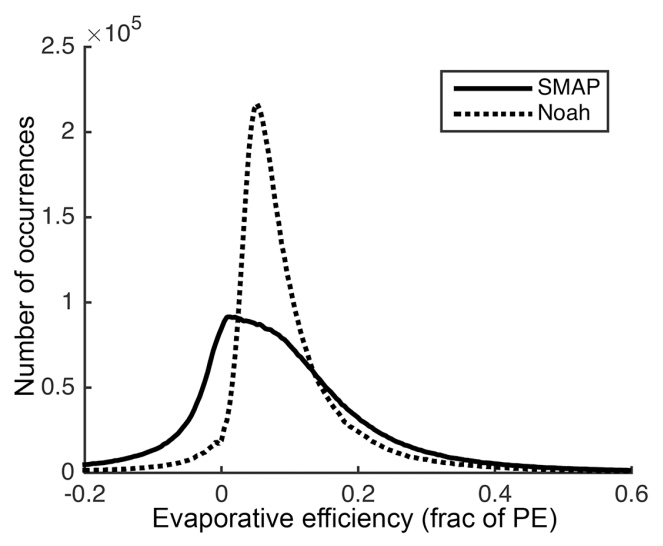

Figure 5. Histograms (200 bins) of evaporative efficiencies observed by SMAP and simulated by Noah.

With these data, we provide continent-wide summaries of the correlation between each variable and the soil drying rates. Because we have nearly 5 million data points, we bin the data according to meteorologic condition or land surface state and plot only median drying rates in each bin. In all cases, bootstrapping is employed to estimate standard errors (Efron and Tibshirani, 1993). Bootstrapped statistics are generated using 500 instances of 100 random samples.

\section{Results}

The drying rates observed by SMAP and simulated by Noah decrease with time since rainfall cessation, consistent with prior results using similar data (McColl et al., 2017a; Shellito et al., 2016b). Thus, as the soil dries following precipitation (Fig. 6a), the median drying rates (Fig. 6b) and median equivalent evaporation rates (Fig. 6c) also decrease. The form of the relationship between drying rate and VSM is described in more detail below.

Although SMAP and Noah both show that drying slows with increased time since rainfall, considerable differences exist. Directly following precipitation, drying rates are higher based on SMAP data than simulated by Noah, by a factor of 2 (Fig. 6b). However, SMAP drying rates decrease more quickly through time. After about 10 days, Noah drying rates are equal to or slightly faster than SMAP rates. The SMAP and Noah equivalent evaporation rates are similar $\left(\sim 0.8 \mathrm{~mm} \mathrm{day}^{-1}\right)$ directly following rainfall (Fig. 6c). Evaporation from Noah occurs over twice the approximate SMAP sensing depth, making up for the differences in drying rate (Fig. 6b) and contributing to higher equivalent evaporation rates than from SMAP after $\sim 5$ days.

In addition to the more rapid decrease in drying rates observed with SMAP shown in Fig. 6, there are also obvious geographic differences between SMAP and Noah drying rates (Fig. 1c and d). Median values of drying rates are calculated in a 25 pixel ( 5 by 5 ) moving window. Data are displayed
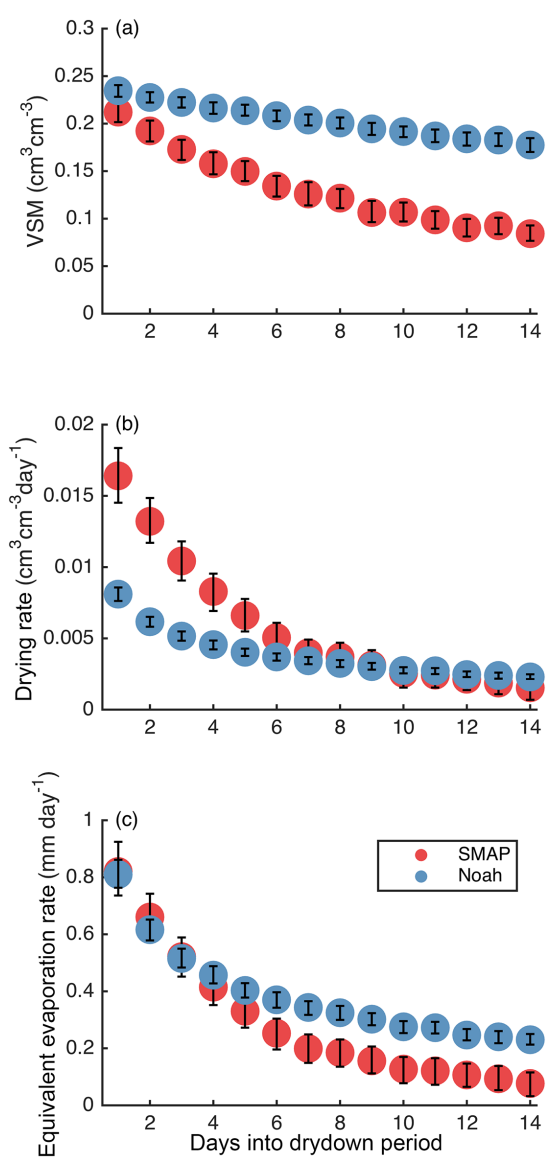

Figure 6. Soil moisture (a), drying rate (b), and equivalent evaporation rate (c) as a function of days into the drydown period. Markers show median values. Error bars show standard error.

at the center of each window whenever at least 100 drying rates are contributing to the median. Median drying rates from SMAP and Noah are similar in the southwest region of the continent where precipitation events are small and infrequent. In these areas, soil moisture remains near its residual value for much of the time. As a result, the large differences that exist immediately after rain events (Fig. 6b) occur infrequently and do not influence the median values shown in Fig. 1c and d. In wetter regions, median drying rates from SMAP are considerably faster than simulated by Noah, at least partly because data from several days after precipitation events affect the median value.

To further investigate the causes of the different drying rates shown above, we consider the variables we understand to control the soil drying process: moisture supply (surface VSM), atmospheric demand (PE), vegetation cover, and soil texture.

\subsection{Soil moisture and PE}

We now investigate how surface soil moisture and PE influence drying rates (Fig. 7). We have divided the drying rate 

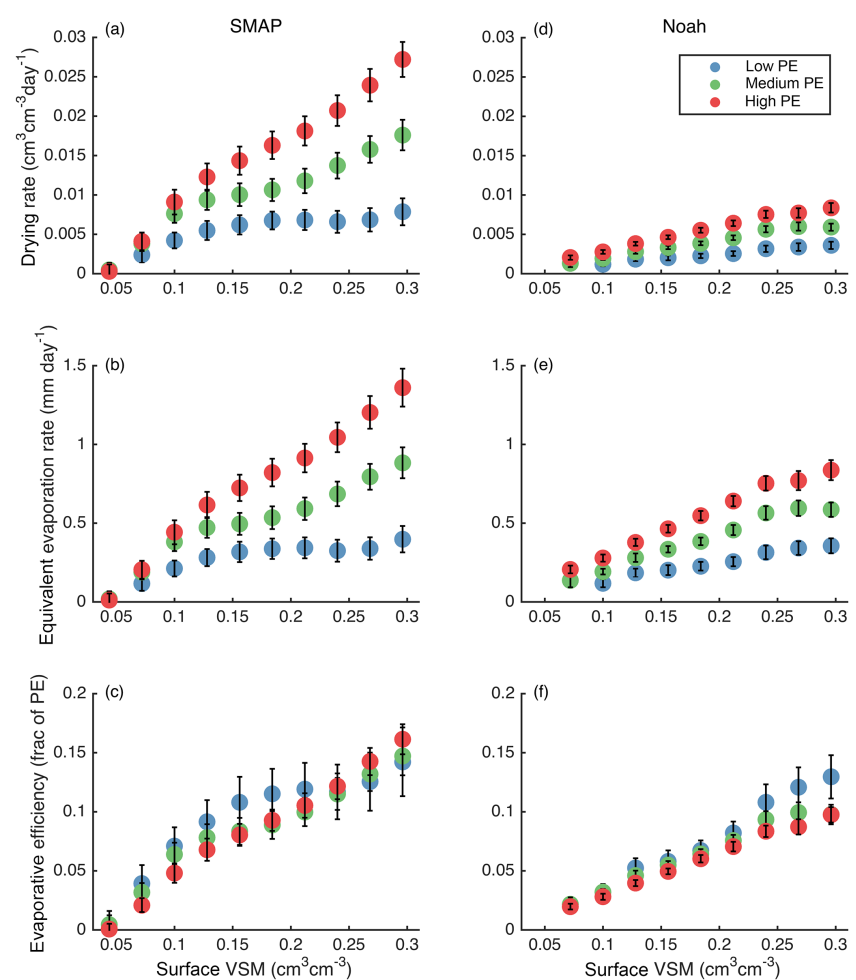

Figure 7. Drying rates and efficiencies for SMAP (a-c) and Noah (d-f) as a function of surface soil moisture content and three PE terciles. The top row shows drying rates, the middle row shows equivalent evaporation rates, and the bottom row shows evaporative efficiencies. Markers show median values. Error bars show standard error.

data into terciles according to PE rate. A single PE value is used for each pair of corresponding SMAP and Noah drying rates, so the terciles are composed of an identical group (in terms of location and time) of observations from SMAP and Noah. We use 10 equal-width bins of increasing soil moisture. VSM is not necessarily equal for corresponding SMAP and Noah observations.

SMAP drying rates are highest when surface VSM and $\mathrm{PE}$ are high. The slowest rates are found when the soil is dry, regardless of PE. Drying rates monotonically increase with surface soil moisture, except in the low PE tercile, where there is a plateau in drying rates for soil moisture exceeding $0.15 \mathrm{~cm}^{3} \mathrm{~cm}^{-3}$. Across most of the range of soil moisture values, drying rates are clearly greater when $\mathrm{PE}$ is high.

Noah drying rates shows similar, though smaller, responses to PE and soil moisture. However, there is no plateau in Noah drying rate when PE is low and soil moisture is high. SMAP shows a larger sensitivity to PE than Noah does and much faster drying rates overall. The differences between SMAP and Noah equivalent evaporation rates (Fig. 7b and e) are smaller than the differences in drying rates because the top model layer thickness in Noah is twice SMAP's sensing depth.
The bottom panels of Fig. 7 show that evaporative efficiency depends almost linearly on soil moisture and is not affected by the PE rate, for both SMAP and Noah. At most VSM levels, the standard errors overlap between PE terciles.

\subsection{Vegetation}

The influence of vegetation on drying rates is complex - vegetation may slow drying due to shading or increase it due to transpiration from the near surface soil. An additional confounding factor is that vegetation tends to be more extensive in the summer months when PE is also high. A positive correlation exists between PE and NDVI across the analysis domain, with the exception of the lowest NDVI quantile (Fig. 8). However, this domain-wide relationship masks strong regional variations. In the humid Upper Midwest, PE and NDVI are strongly positively correlated. In contrast, NDVI is always low and PE varies greatly throughout the year in the desert southwest. Given that higher PE leads to higher drying rates (Sect. 3.1), we control for this effect by considering evaporative efficiency, which is normalized by PE.

Figure 9 illustrates the relationship between vegetation amount (as indicated by NDVI) and drying rates, equivalent evaporation rates, and evaporative efficiencies. Corresponding SMAP and Noah observations are divided into 10 vegetation quantiles. The data are further divided into wet, transition, and dry soil (three quantiles), as observed by SMAP or simulated by Noah. Thus, each pair of corresponding SMAP and Noah values is included in the same vegetation quantile, but not necessarily in the same VSM quantile.

When the soil is dry, SMAP drying and equivalent evaporation rates are low regardless of vegetation level (Fig. 9a and b), consistent with the results shown above (Fig. 7). Similarly, the evaporative efficiency is very low for dry soil regardless of vegetation amount. For the intermediate soil moisture tercile, SMAP drying and evaporation rates both decrease as vegetation cover increases. The wettest tercile exhibits the lowest rates with intermediate amounts of vegetation cover and higher rates with both less and more vegetation. Once the drying rates are normalized by PE however, the relationship between soil drying and vegetation is more consistent across soil moisture levels (Fig. 9c): evaporative efficiency consistently decreases as vegetation increases, unless the soil is dry and drying rates are effectively zero. Evaporative efficiency decreases by a factor of 2 to 3 between the lowest and the highest vegetation quantiles.

Noah simulations exhibit little or no relationship between vegetation and drying or evaporation rates (Fig. 9d and e). For the wettest soil tercile, evaporative efficiency does appear to decrease with vegetation cover, although the sensitivity is much less than found using SMAP observations. 
(a)

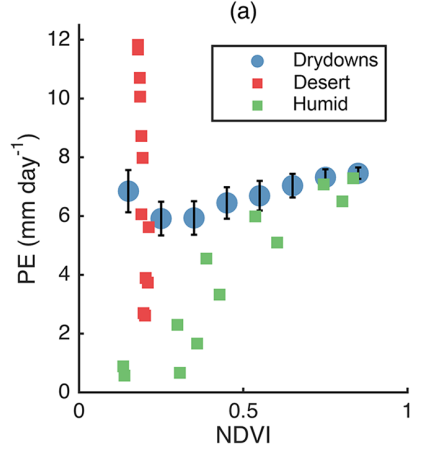

(b)

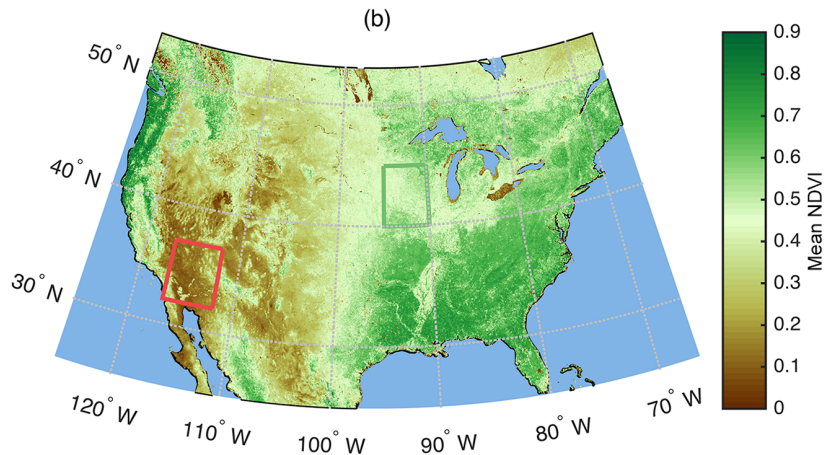

Figure 8. (a) Circles show median PE as a function of eight equal-width bins of increasing NDVI for all drydowns used in this study. Squares show average monthly relationships between PE and NDVI in two regions. (b) Extent indicators show locations of two regions.
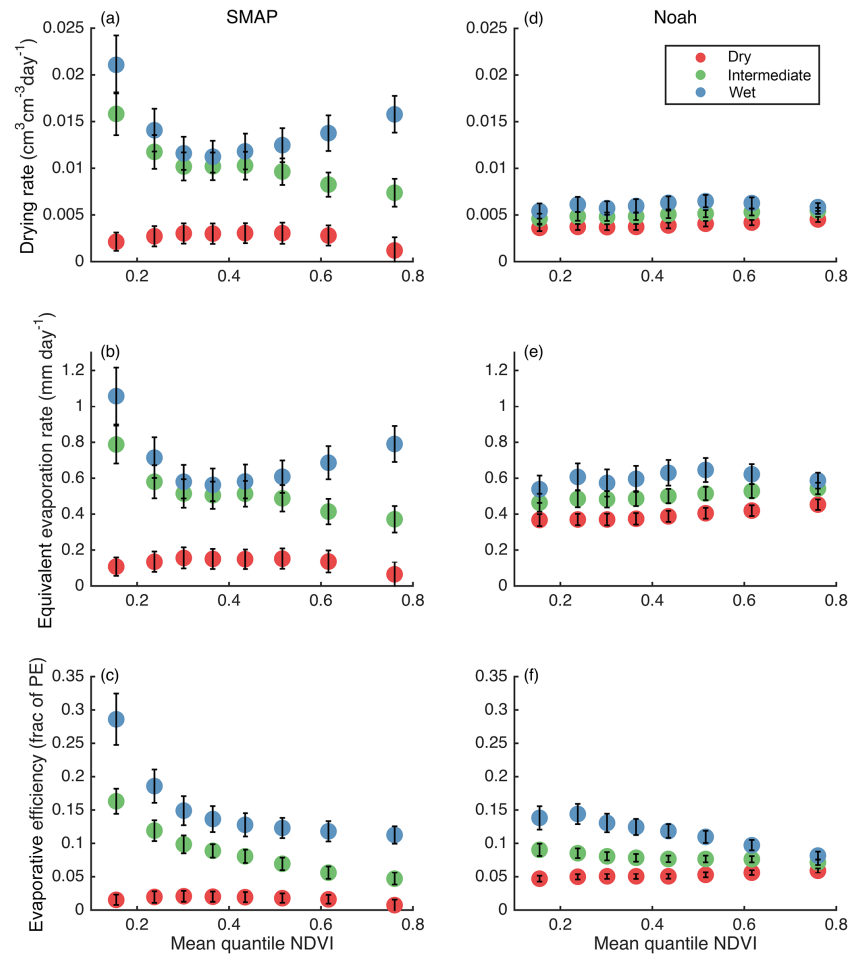

Figure 9. As in Fig. 7, but drying rates are a function of NDVI (eight quantiles, on $x$-axis) and surface soil moisture content (three quantiles, by color).

\subsection{Soil texture}

The four main soil types in the conterminous United States (sand, sandy loam, loam, and silt loam) all exhibit similar drying dynamics as observed by SMAP. Figure 10a-c show that differences between the four texture classes are small: drying rates and equivalent evaporation rates are slightly higher for loam, especially in wet soils, and slightly lower for silt loam, especially in soils of intermediate wetness (Fig. 10a and b). Only minor differences exist between other texture types. The observed differences diminish slightly when dry-
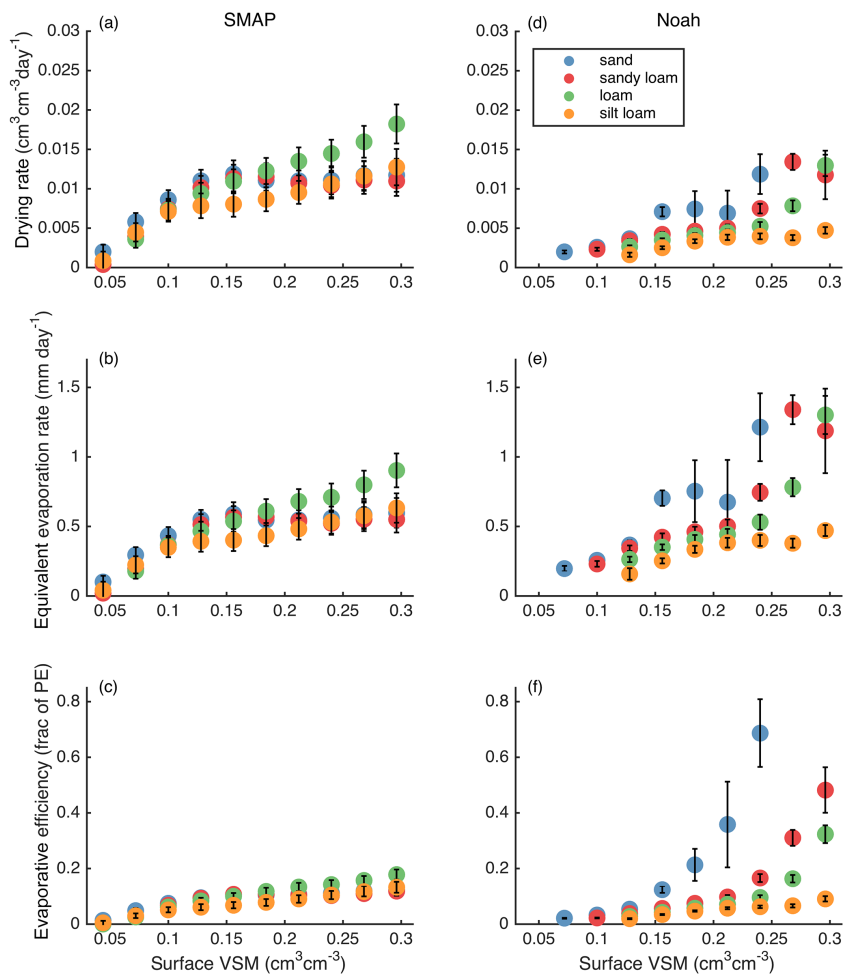

Figure 10. As in Fig. 7, but drying rates are divided among the four most prevalent soil texture classes. Markers are omitted if fewer than $0.05 \%$ of the total calculated drying rates fall within the VSM/soil texture category.

ing is expressed as evaporative efficiency (Fig. 10c), suggesting that some portion of the observed differences in drying and evaporation rates are due to spatial variations in PE that covary with soil texture.

In contrast, drying dynamics simulated by Noah (Fig. 10df) exhibit large differences between the four most common texture classes. The coarsest texture (sand) shows the fastest drying rates, evaporation rates, and evaporative efficiencies. The finest texture (silt loam) shows the slowest. In wet soil 

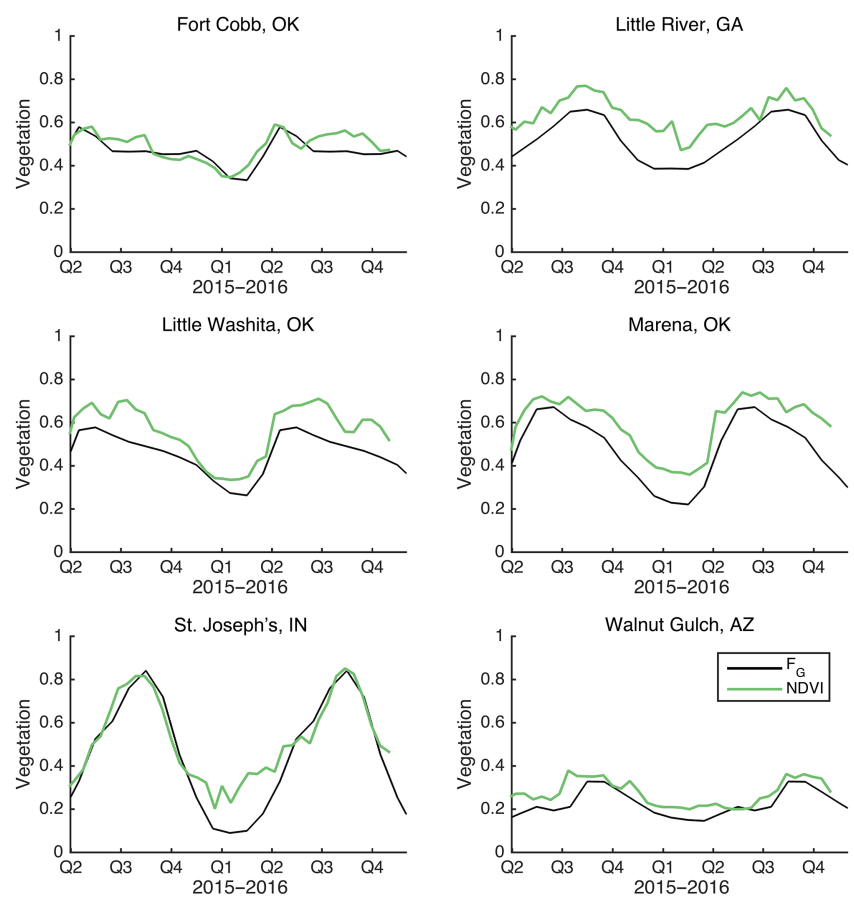

Figure 11. NDVI and $F_{G}$ at six sites in the study domain.

conditions, the median evaporative efficiency for sand is approximately 5 times higher than that of other texture classes.

\subsection{Inconsistencies between SMAP and Noah}

SMAP drying dynamics are dependent on environmental states observed at the time of each overpass. Noah simulations, however, depend on a vegetation parameter that has been calculated from climatology: its $F_{G}$ parameter is derived from 5 years of NDVI observations (Gutman and Ignatov, 1998). In addition, Noah results reflect the behavior of the $10 \mathrm{~cm}$ surface layer, whereas SMAP nominally senses only the top $5 \mathrm{~cm}$. These two inconsistencies must be considered carefully to fairly compare SMAP and Noah results.

\subsubsection{NDVI vs. $F_{G}$}

The SMAP satellite observes varying land surface conditions. NDVI provides one estimate of vegetation status at the time of each SMAP retrieval. In contrast, the $F_{G}$ parameter used in Noah is based on the climatology of NDVI (Gutman and Ignatov, 1998). Therefore, the effect of vegetation on Noah model states is simplified: the model simulations cannot respond to deviations from climatology. Abnormally high or low vegetation cover that may exist in any year as indicated by NDVI (which was used for the analysis shown in Fig. 9) will not affect the Noah simulation.

It is critical to evaluate if Noah's limited sensitivity to vegetation (Fig. 9) is due to the potential mismatch between instantaneous (used in our analysis) and climatological (used in
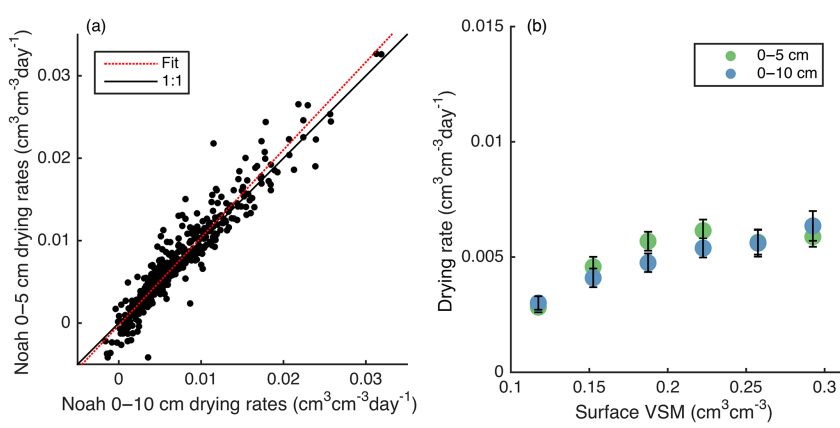

Figure 12. (a) Scatter plot comparing Noah drying rates between simulations with different surface layer depths. $R=0.93$. Best fit intercept $=0$, slope $=1.06$. (b) Drying rate as a function of VSM for six quantiles using the two Noah simulation depths. Markers show median values. Error bars show standard errors.

the Noah simulation) vegetation state. The alternative is that the lack of sensitivity to vegetation is attributable to the Noah model structure itself. In Fig. 11, we show observed NDVI and Noah's climatological $F_{G}$ at six sites for the period of record of SMAP data analyzed here. Because the NDVI scaling parameters used to convert NDVI to $F_{G}$ (Eq. 1) are close to 0 and 1 (Youlong Xia, personal communication, 2017), the two variables can be plotted on the same axis. There are no clear departures from climatology. This suggests the Noah model structure is the source of the limited sensitivity of drying to vegetation amount, not the use of vegetation climatology. Furthermore, recreating Fig. 9 using $F_{G}$ as the covariate instead of NDVI does not substantially change the results (not shown).

\subsubsection{Noah simulation depth}

Drying dynamics may be affected by the depth of soil being sensed or modeled (Rondinelli et al., 2015; Shellito et al., 2016b). We use the six supplementary simulations described in Sect. 2.1.5 to compare the drying characteristics of Noah simulations from a $10 \mathrm{~cm}$ surface layer against a $5 \mathrm{~cm}$ surface layer. The former is the standard setup and was used for the results shown above. Figure 12 shows that the modeled dependence of drying rates on surface VSM is nearly identical between the simulations with different surface layer depths. Drying rates increase by only $6 \%$ when the shallower layer is used. This slight change does shift Noah drying rates towards the trends documented by SMAP observations, but it is not large enough to account for the approximately 4 -fold differences between the two shown in Fig. 7a and d. These results suggest that the differences in dynamics between SMAP and Noah are not attributable to the difference in depth between the two sources, but instead to the model's structure itself. 


\section{Discussion}

The remotely sensed data from NASA's SMAP mission, combined with modeled data, provide insight into the environmental factors that affect surface soil moisture dynamics and direct evaporation from soil. The results presented here are based on correlations between environmental factors and soil drying rates, so it is not possible to prove cause-effect relationships exist. However, the results are consistent with ground-based observations (e.g., Kurc and Small, 2004) and physics-based relationships included in models (e.g., Laio et al., 2001). Therefore, results confirm that these fundamental relationships exist on the continental scale.

SMAP data show that the land surface dries rapidly immediately after rainfall. With time, the soil dries and the drying rate slows, the latter approaching zero after $\sim 10$ days. Noah simulations also exhibit this trend, but the drying rates are slower directly after rainfall and persist at nonzero values for longer than SMAP rates do, indicating a more linear drying process (Fig. 6).

To constrain the factors affecting the drying process, we simultaneously consider the supply of water (soil moisture) and the atmospheric demand for it (PE). When the surface soil is wet, only atmospheric demand should limit evaporation rates (stage one evaporation). When the surface soil is dry, moisture supply further restricts evaporation rates (stage two evaporation). Our study finds that, on SMAP spatial and temporal scales, the satellite is observing a system that is predominantly water-limited (McColl et al., 2017a). This is supported by the following observations (Fig. 7).

1. In most cases, drying and evaporation rates are linearly related to soil moisture content. Such consistent dependence on moisture supply indicates water-limited conditions. In contrast, energy-limited conditions would show evaporation rates to be insensitive to soil moisture.

2. The sensitivity of drying rates to soil moisture depends on PE. This, along with Fig. 4, which shows an approximately $1: 1$ ratio of drying rates to evaporation rates, supports the supposition that drying rates are controlled mainly by evaporation rates instead of by drainage or diffusion rates, as they would be in an energy-limited environment.

3. In the low PE tercile, there is a plateau in drying rates when soil moisture exceeds $0.15 \mathrm{~cm}^{3} \mathrm{~cm}^{-3}$ (Fig. 7a). Such a plateau could indicate an energy-limited environment. However, the evaporative efficiency does not also reach a plateau at high VSM. This suggests variations in PE within the lowest PE tercile are responsible for the plateau observed in Fig. 7a and b - the wettest soils are found in environments with the very lowest PE rates.

Noah simulations are consistent with the results from SMAP data. In general, drying rates from Noah are much lower than those from SMAP, but the equivalent evaporation rates from Noah are the same as or higher than those from SMAP (Fig. 6c) because the layer one depth is greater and soil moisture levels are generally higher in Noah (Fig. 6a). Noah drying rates do not plateau in the low PE tercile, further supporting the idea that the system is water-limited.

It is possible that SMAP drying rates are slightly exaggerated due to decreases in L-band sensing depth that accompany wet soil. After rainfall, moisture in the top couple of centimeters could dominate the signal, leading to the entire $0-5 \mathrm{~cm}$ sensing depth being assigned a moisture level that is only present at the very surface. As the soil dries and becomes more evenly distributed within the sensing depth, such abnormalities would dissipate.

The calculated values for evaporative efficiency are quite low (Fig. 5); $90 \%$ of values are below $\sim 0.25$. This suggests evaporation from the surface satisfies only a small fraction of the atmospheric demand. The fraction is not larger for one or more of the following reasons: (1) on this spatial and temporal scale, evaporation is highly water-limited; (2) most plant roots are deeper than $\sim 5 \mathrm{~cm}$, so transpiration draws water from depths below the surface layer and thus does not contribute to the SMAP-based accounting of drying analyzed here; (3) similarly, if any evaporation draws moisture from below SMAP's sensing depth, it will not be accounted for here; and (4) the sampling interval of SMAP is too low to capture the fastest evaporation rates, which occur soon after rainfall. Only $6.5 \%$ of the calculated drying rates include an observation from within the first $12 \mathrm{~h}$ after precipitation, when the fastest drying and highest evaporative efficiency is likely to occur. For example, in Fig. 3, the first observation, $t_{1}$, is almost 2 days after rainfall cessation.

While VSM and PE clearly influence soil drying, SMAP observations also show that vegetation plays an important role in determining soil drying rates. These effects are most obvious once drying rates are normalized by PE because vegetation (as indicated by NDVI) and PE both tend to be greatest in the summer months (Fig. 8). Evaporative efficiency decreases with increasing vegetation cover (Fig. 9c), unless the soil is dry and evaporative efficiency is close to zero. This means that at a given moisture level and PE rate, the surface soil of a parcel of land will dry more slowly if it has vegetation on it than if it does not. This is consistent with ground-based observations that show direct evaporation can be limited by vegetation (e.g., Breshears et al., 1998).

In comparison to SMAP, the effects of vegetation on drying in Noah are minimal (Fig. 9e-f). These results can be understood given the model's formulation of evapotranspiration (Chen and Dudhia, 2001). Direct soil evaporation only occurs over the fraction of land surface not shaded by the canopy $\left(1-F_{G}\right)$, so evaporation decreases with more vegetation. Transpiration only occurs over the fraction of land surface that has a canopy $\left(F_{G}\right)$, so transpiration increases with more vegetation. Our results show these two effects are balanced in dry and intermediate wetness soils. Soil in the 
wettest tercile exhibit slightly higher evaporative efficiencies from bare soil than from vegetated soil (Fig. 9f). The Noah results indicate that in the top $10 \mathrm{~cm}$ of soil, moisture from rainfall enhances evaporation from bare ground more than it does transpiration from vegetated ground.

Vegetation effects are much greater as observed by SMAP than simulated by Noah. Therefore, the direct evaporation flux in Noah should be greater (at a given VSM and PE), which would result in higher surface drying efficiencies when vegetation is sparse. Betts et al. (1997) and Ek et al. (2003) both modified Noah's bare soil evaporation function to magnify the decrease in evaporation as the surface dries. The SMAP observations suggest further adjustments are needed.

The results in Fig. 10 show that the sensitivity to soil texture is too high in Noah. SMAP shows only small differences in drying dynamics related to texture classes (here and McColl et al., 2017a), whereas Noah simulations indicate variations of a factor of 5 between sand and other texture classes. Noah-simulated results conform to the expectation that coarser soils (sand and sandy loam) dry faster than finegrained soils (silt loam). (Soil infiltration and redistribution parameters are indeed selected according to texture class; Chen and Dudhia, 2001). On the contrary, our SMAP-based results show the role of soil textures to be less important than the other factors analyzed here. It is possible that improved soil texture maps could bring SMAP and Noah results into closer agreement, but the heterogeneity of soils even within a single texture class (Gutmann and Small, 2005) makes it unlikely that the solution will come from improving texture maps alone.

The differences in behavior between SMAP and Noah can also partially be attributed to differences in sensing and simulation depths. We expect thicker surface layer dynamics to be dampened when compared to a thinner layer (e.g., Rondinelli et al., 2015). However, changing Noah's layer one soil depth from $0-10$ to $0-5 \mathrm{~cm}$ only increases soil drying rates by $6 \%$ (Fig. 12), implying that the model structure itself prevents Noah from accurately reproducing the surface soil moisture dynamics observed by SMAP.

\section{Conclusion}

SMAP-observed and Noah-simulated soil moisture and drying rates decrease with time since precipitation. SMAP drying rates are faster than Noah-simulated drying rates in the first 8 days after rainfall, but slower afterwards. Because Noah's top soil layer is twice the depth that SMAP senses, its equivalent evaporation rates are nearly the same as SMAP's soon after precipitation and higher afterwards.

SMAP-observed and Noah-simulated soil drying rates both vary linearly with soil moisture content, evidence that continental-scale soil moisture dynamics operate in a waterlimited system.
Equivalent evaporation rates from SMAP and Noah rarely exceed $1 \mathrm{~mm}$ day $^{-1}$. Expressed as evaporative efficiency, $90 \%$ of the calculated rates fall below 0.27 (SMAP) or 0.21 (Noah). These values are far below unity, providing further evidence of a water-limited environment. However, accounting for transpiration of water from below the 5 or $10 \mathrm{~cm}$ surface layer would shift total $E_{\mathrm{T}}$ efficiencies closer to 1 .

SMAP and Noah both show that high atmospheric demand for moisture (high PE) increases the sensitivity of drying rates to soil moisture content.

More vegetation amount, indicated by higher NDVI, decreases the surface drying efficiency: SMAP shows a 3-fold evaporation efficiency decrease between sparsely vegetated and densely vegetated pixels. This suggests that the decreases in evaporation from canopy shading are not offset by increases in transpiration from the shallow soil layer. Noah shows a much smaller decrease in evaporative efficiency, only for wet soils, suggesting a deficiency in the model structure.

Soil texture class has a small influence on SMAP drying dynamics. Noah drying dynamics are strongly affected by soil texture class, as prescribed by its soil hydraulic property parameterization.

This study has demonstrated that SMAP exhibits unprecedented soil drying sensitivity across at least three of the dimensions analyzed (soil moisture supply, PE rate, and vegetation cover) that is largely missed by Noah (e.g., Figs. 6, 7, and 9). This provides encouraging evidence of the potential to use SMAP observations to improve model portrayals of soil drying.

Data availability. The SMAP retrievals (https://doi.org/10.5067/ ZRO7EXJ8O3XI, O'Neill et al., 2016), NLDAS-2 forcings (https: //doi.org/10.5067/6J5LHHOHZHN4, Xia et al., 2012d), NLDAS-2 Noah simulations (https://doi.org/10.5067/47Z13FNQODKV, Xia et al., 2012c), and MODIS NDVI data (https://doi.org/10.5067/ MODIS/MOD13A2.006, Didan, 2015) used in this study can be obtained from public repositories.

Competing interests. The authors declare that they have no conflict of interest.

Acknowledgements. The authors would like to thank Andrew Badger for downloading and processing MODIS NDVI data.

Edited by: Shraddhanand Shukla

Reviewed by: two anonymous referees 


\section{References}

Allen, R.: Using the FAO-56 dual crop coefficient method over an irrigated region as part of an evapotranspiration intercomparison study, J. Hydrol., 229, 27-41, https://doi.org/10.1016/S00221694(99)00194-8, 2000.

Betts, A. K., Chen, F., Mitchell, K. E., and Janjić, Z. I.: Assessment of the Land Surface and Boundary Layer Models in Two Operational Versions of the NCEP Eta Model Using FIFE Data, Mon. Weather Rev., 125, 2896-2916, https://doi.org/10.1175/15200493(1997)125<2896:AOTLSA>2.0.CO;2, 1997.

Breshears, D. D., Nyhan, J. W., Heil, C. E., and Wilcox, B. P.: Effects of Woody Plants on Microclimate in a Semiarid Woodland: Soil Temperature and Evaporation in Canopy and Intercanopy Patches, Int. J. Plant Sci., 159, 1010-1017, https://doi.org/10.1086/314083, 1998.

Campbell, G. and Norman, J.: Introduction to Enviromental Biophysics, 2nd ed., Springer-Verlag, New York, 1998.

Campbell, G. S.: Simple Method for Determining Unsaturated Conductivity from Moisture Retention Data, Soil Sci., 117, 311-314, 1974.

Cavanaugh, M. L., Kurc, S. A., and Scott, R. L.: Evapotranspiration partitioning in semiarid shrubland ecosystems: a two-site evaluation of soil moisture control on transpiration, Ecohydrology, 4, 671-681, https://doi.org/10.1002/eco.157, 2011.

Chan, S. K., Bindlish, R., E. O’Neill, P., Njoku, E., Jackson, T., Colliander, A., Chen, F., Burgin, M., Dunbar, S., Piepmeier, J., Yueh, S., Entekhabi, D., Cosh, M. H., Caldwell, T., Walker, J., Wu, X., Berg, A., Rowlandson, T., Pacheco, A., McNairn, H., Thibeault, M., Martinez-Fernandez, J., Gonzalez-Zamora, A., Seyfried, M., Bosch, D., Starks, P., Goodrich, D., Prueger, J., Palecki, M., Small, E. E., Zreda, M., Calvet, J.-C., Crow, W. T., and Kerr, Y.: Assessment of the SMAP Passive Soil Moisture Product, IEEE Geosci. Remote S., 54, 4994-5007, https://doi.org/10.1109/TGRS.2016.2561938, 2016.

Chan, S. K., Bindlish, R., O’Neill, P., Jackson, T., Njoku, E., Dunbar, S., Chaubell, J., Piepmeier, J., Yueh, S., Entekhabi, D., Colliander, A., Chen, F., Cosh, M. H., Caldwell, T., Walker, J., Berg, A., McNairn, H., Thibeault, M., Martínez-Fernández, J., Uldall, F., Seyfried, M., Bosch, D., Starks, P., Holifield Collins, C., Prueger, J., van der Velde, R., Asanuma, J., Palecki, M., Small, E. E., Zreda, M., Calvet, J., Crow, W. T., and Kerr, Y.: Development and assessment of the SMAP enhanced passive soil moisture product, Remote Sens. Environ., 204, 931-941, https://doi.org/10.1016/j.rse.2017.08.025, 2018.

Chen, F. and Dudhia, J.: Coupling an advanced land surfacehydrology model with the Penn State-NCAR MM5 modeling system. Part I: Model implementation and sensitivity, Mon. Weather Rev., 129, 569-585, https://doi.org/10.1175/15200493(2001)129<0569:CAALSH>2.0.CO;2, 2001.

Clapp, R. B. and Hornberger, G. M.: Empirical equations for some soil hydraulic properties, Water Resour. Res., 14, 601, https://doi.org/10.1029/WR014i004p00601, 1978.

Cosby, B. J., Hornberger, G. M., Clapp, R. B., and Ginn, T. R.: A Statistical Exploration of the Relationships of Soil Moisture Characteristics to the Physical Properties of Soils, Water Resour. Res., 20, 682-690, https://doi.org/10.1029/WR020i006p00682, 1984.

Cosgrove, B. A., Lohmann, D., Mitchell, K. E., Houser, P. R., Wood, E. F., Schaake, J. C., Robock, A., Marshall, C.,
Sheffield, J., Duan, Q., Luo, L., Higgins, R. W., Pinker, R. T., Tarpley, J. D., and Meng, J.: Real-time and retrospective forcing in the North American Land Data Assimilation System (NLDAS) project, J. Geophys. Res., 108, 8842, https://doi.org/10.1029/2002JD003118, 2003.

Daly, C., Neilson, R. P., and Phillips, D. L.: A statisticaltopographic model for mapping climatological precipitation over mountainous terrain, J. Appl. Meteorol., 33, 140-158, https://doi.org/10.1175/15200450(1994)033<0140:ASTMFM>2.0.CO;2, 1994.

Detto, M., Montaldo, N., Albertson, J. D., Mancini, M., and Katul, G.: Soil moisture and vegetation controls on evapotranspiration in a heterogeneous Mediterranean ecosystem on Sardinia, Italy, Water Resour. Res., 42, W08419, https://doi.org/10.1029/2005WR004693, 2006.

Didan, K.: MOD13A2 MODIS/Terra Vegetation Indices 16-Day L3 Global $1 \mathrm{~km}$ SIN Grid V006, distributed by NASA EOSDIS LP DAAC, available at: https://doi.org/10.5067/MODIS/MOD13A2.006 (last access: December 2016), 2015.

Efron, B. and Tibshirani, R.: An Introduction to the Bootstrap, Chapman \& Hall, New York, 1993.

Ek, M. B., Mitchell, K. E., Lin, Y., Rogers, E., Grunmann, P., Koren, V., Gayno, G., and Tarpley, J. D.: Implementation of Noah land surface model advances in the National Centers for Environmental Prediction operational mesoscale Eta model, J. Geophys. Res., 108, 8851, https://doi.org/10.1029/2002JD003296, 2003.

Entekhabi, D., Rodriguez-Iturbe, I., and Castelli, F.: Mutual interaction of soil moisture state and atmospheric processes, J. Hydrol., 184, 3-17, https://doi.org/10.1016/0022-1694(95)02965-6, 1996.

Entekhabi, D., Njoku, E. G., O’Neill, P. E., Kellogg, K. H., Crow, W. T., Edelstein, W. N., Entin, J. K., Goodman, S. D., Jackson, T. J., Johnson, J., Kimball, J., Piepmeier, J. R., Koster, R. D., Martin, N., McDonald, K. C., Moghaddam, M., Moran, S., Reichle, R., Shi, J. C., Spencer, M. W., Thurman, S. W., Tsang, L., and Van Zyl, J.: The Soil Moisture Active Passive (SMAP) Mission, Proc. IEEE, 98, 704-716, https://doi.org/10.1109/JPROC.2010.2043918, 2010.

Entekhabi, D., Yueh, S., O’Neill, P. E., Kellogg, K. H., Allen, A., Bindlish, R., Brown, M., Chan, S., Colliander, A., Crow, W. T., Das, N., De Lannoy, G., Dunbar, R. S., Edelstein, W. N., Entin, J. K., Escobar, V., Goodman, S. D., Jackson, T. J., Jai, B., and Johnson, J.: SMAP Handbook Soil Moisture Active Passive, Mapping Soil Moisture Freeze/Thaw from Space, Pasadena, CA, 2014.

Federer, C. A., Vörösmarty, C., and Fekete, B.: Sensitivity of Annual Evaporation to Soil and Root Properties in Two Models of Contrasting Complexity, J. Hydrometeorol., 4, 1276-1290, https://doi.org/10.1175/15257541(2003)004<1276:SOAETS>2.0.CO;2, 2003.

Guswa, A. J., Celia, M. A., and Rodriguez-Iturbe, I.: Models of soil moisture dynamics in ecohydrology: A comparative study, Water Resour. Res., 38, 5-15, https://doi.org/10.1029/2001WR000826, 2002.

Gutman, G. and Ignatov, A.: The derivation of the green vegetation fraction from NOAA/AVHRR data for use in numerical weather prediction models, Int. J. Remote Sens., 19, 1533-1543, https://doi.org/10.1080/014311698215333, 1998. 
Gutmann, E. D. and Small, E. E.: The effect of soil hydraulic properties vs. soil texture in land surface models, Geophys. Res. Lett., 32, L02402, https://doi.org/10.1029/2004GL021843, 2005.

Herbst, M., Kappen, L., Thamm, F., and Vanselow, R.: Simultaneous measurements of transpiration, soil evaporation and total evaporation in a maize field in northern Germany, J. Exp. Bot., 47, 1957-1962, https://doi.org/10.1093/jxb/47.12.1957, 1996.

Jackson, T. J., Bindlish, R., Cosh, M. H., Zhao, T., Starks, P. J., Bosch, D. D., Seyfried, M., Moran, M. S., Goodrich, D. C., Kerr, Y. H., and Leroux, D.: Validation of Soil Moisture and Ocean Salinity (SMOS) Soil Moisture Over Watershed Networks in the U.S., IEEE Geosci. Remote S., 50, 1530-1543, https://doi.org/10.1109/TGRS.2011.2168533, 2012.

Kerr, Y. H.: Soil moisture from space: Where are we?, Hydrogeol. J., 15, 117-120, https://doi.org/10.1007/s10040-006-00953, 2006.

Kool, D., Agam, N., Lazarovitch, N., Heitman, J. L., Sauer, T. J., and Ben-Gal, A.: A review of approaches for evapotranspiration partitioning, Agric. For. Meteorol., 184, 56-70, https://doi.org/10.1016/j.agrformet.2013.09.003, 2014.

Koster, R. D., Dirmeyer, P. A., Guo, Z. C., Bonan, G., Chan, E., Cox, P., Gordon, C. T., Kanae, S., Kowalczyk, E., Lawrence, D., Liu, P., Lu, C. H., Malyshev, S., McAvaney, B., Mitchell, K., Mocko, D., Oki, T., Oleson, K., Pitman, A., Sud, Y. C., Taylor, C. M., Verseghy, D., Vasic, R., Xue, Y. K., Yamada, T., and Team, G.: Regions of strong coupling between soil moisture and precipitation, Science, 305, 1138-1140, https://doi.org/10.1126/science.1100217, 2004.

Kurc, S. A. and Small, E. E.: Dynamics of evapotranspiration in semiarid grassland and shrubland ecosystems during the summer monsoon season, central New Mexico, Water Resour. Res., 40, W09305, https://doi.org/10.1029/2004WR003068, 2004.

Kurc, S. A. and Small, E. E.: Soil moisture variations and ecosystem-scale fluxes of water and carbon in semiarid grassland and shrubland, Water Resour. Res., 43, W06416, https://doi.org/10.1029/2006WR005011, 2007.

Laio, F., Porporato, A., Ridolfi, L., and Rodriguez-Iturbe, I.: Plants in water-controlled ecosystems: active role in hydrologic processes and response to water stress II. Probabilistic soil moisture dynamics, Adv. Water Resour., 24, 707-723, https://doi.org/10.1016/S0309-1708(01)00005-7, 2001.

Mahfouf, J. F. and Noilhan, J.: Comparative Study of Various Formulations of Evaporations from Bare Soil Using In Situ Data, J. Appl. Meteorol., 30, 1354-1365, https://doi.org/10.1175/15200450(1991)030<1354:CSOVFO > 2.0.CO;2, 1991.

Mahrt, L. and Ek, M.: The Influence of Atmospheric Stability on Potential Evaporation, J. Clim. Appl. Meteorol., 23, 222-234, https://doi.org/10.1175/15200450(1984)023<0222:TIOASO>2.0.CO;2, 1984.

McColl, K. A., Wang, W., Peng, B., Akbar, R., Short Gianotti, D. J., Lu, H., Pan, M., and Entekhabi, D.: Global characterization of surface soil moisture drydowns, Geophys. Res. Lett., 44, 36823690, https://doi.org/10.1002/2017GL072819, 2017a.

McColl, K. A., Alemohammad, S. H., Akbar, R., Konings, A. G., Yueh, S., and Entekhabi, D.: The global distribution and dynamics of surface soil moisture, Nat. Geosci., 10, 100-104, https://doi.org/10.1038/ngeo2868, 2017b.

Miller, D. A. and White, R. A.: A Conterminous United States Multilayer Soil Characteristics Dataset for Regional Climate and Hydrology Modeling, Earth Interact., 2, 1-26, https://doi.org/10.1175/10873562(1998)002<0001:ACUSMS>2.3.CO;2, 1998.

Mitchell, K. E., Lohmann, D., Houser, P. R., Wood, E. F., Schaake, J. C., Robock, A., Cosgrove, B. A., Sheffield, J., Duan, Q. Y., Luo, L. F., Higgins, R. W., Pinker, R. T., Tarpley, J. D., Lettenmaier, D. P., Marshall, C. H., Entin, J. K., Pan, M., Shi, W., Koren, V., Meng, J., Ramsay, B. H., and Bailey, A. A.: The multiinstitution North American Land Data Assimilation System (NLDAS): Utilizing multiple GCIP products and partners in a continental distributed hydrological modeling system, J. Geophys. Res., 109, 1-32, https://doi.org/10.1029/2003JD003823, 2004.

Monteith, J. L. and Unsworth, M.: Principles of environmental physics, 4th ed., Academic Press, Oxford, 2013.

Njoku, E. G. and Entekhabi, D.: Passive microwave remote sensing of soil moisture, J. Hydrol., 184, 101-129, https://doi.org/10.1016/0022-1694(95)02970-2, 1996.

Njoku, E. G. and Kong, J.-A.: Theory for passive microwave remote sensing of near-surface soil moisture, J. Geophys. Res., 82 , 3108-3118, https://doi.org/10.1029/JB082i020p03108, 1977.

O’Neill, P. E., Chan, S., Njoku, E. G., Jackson, T., and Bindlish, R.: SMAP Enhanced L3 Radiometer Global Daily 9 km EASE-Grid Soil Moisture Version 1, Boulder, Colorado USA, NASA National Snow and Ice Data Center Distributed Active Archive Center, available at: https://doi.org/10.5067/ZRO7EXJ8O3XI (last access: March 2017), 2016.

Penman, H. L.: Natural Evaporation from Open Water, Bare Soil and Grass, Proc. R. Soc. A Math. Phys. Eng. Sci., 193, 120-145, https://doi.org/10.1098/rspa.1948.0037, 1948.

Porporato, A., Daly, E., and Rodriguez-Iturbe, I.: Soil Water Balance and Ecosystem Response to Climate Change, Am. Nat. 164, 625-632, https://doi.org/10.1086/424970, 2004.

Rodriguez-Iturbe, I.: Ecohydrology: A hydrologic perspective of climate-soil-vegetation dynamies, Water Resour. Res., 36, 3-9, https://doi.org/10.1029/1999WR900210, 2000.

Rondinelli, W. J., Hornbuckle, B. K., Patton, J. C., Cosh, M. H., Walker, V. A., Carr, B. D., and Logsdon, S. D.: Different Rates of Soil Drying after Rainfall Are Observed by the SMOS Satellite and the South Fork in situ Soil Moisture Network, J. Hydrometeorol., 16, 889-903, https://doi.org/10.1175/JHM-D-14-0137.1, 2015.

Schenk, H. J. and Jackson, R. B.: Rooting depths, lateral root spreads and below-ground/above-ground allometries of plants in water-limited ecosystems, J. Ecol., 90, 480-494, https://doi.org/10.1046/j.1365-2745.2002.00682.x, 2002.

Shellito, P. J., Small, E. E., and Cosh, M. H.: Calibration of Noah Soil Hydraulic Property Parameters Using Surface Soil Moisture from SMOS and Basinwide In Situ Observations, J. Hydrometeorol., 17, 2275-2292, https://doi.org/10.1175/JHM-D15-0153.1, 2016a.

Shellito, P. J., Small, E. E., Colliander, A., Bindlish, R., Cosh, M. H., Berg, A. A., Bosch, D. D., Caldwell, T. G., Goodrich, D. C., McNairn, H., Prueger, J. H., Starks, P. J., van der Velde, R., and Walker, J. P.: SMAP soil moisture drying more rapid than observed in situ following rainfall events, Geophys. Res. Lett., 43, 8068-8075, https://doi.org/10.1002/2016GL069946, 2016 b.

Stannard, D. I. and Weltz, M. A.: Partitioning evapotranspiration in sparsely vegetated rangeland using a 
portable chamber, Water Resour. Res., 42, W02413, https://doi.org/10.1029/2005WR004251, 2006.

Tuttle, S. and Salvucci, G.: Empirical evidence of contrasting soil moisture-precipitation feedbacks across the United States, Science, 352, 825-828, https://doi.org/10.1126/science.aaa7185, 2016.

Van Genuchten, M. T.: A Closed-Form Equation for Predicting the Hydraulic Conductivity of Unsaturated Soils, Soil Sci. Soc. Am. J., 44, 892-898, 1980.

Viterbo, P. and Betts, A. K.: Impact of the ECMWF reanalysis soil water on forecasts of the July 1993 Mississippi flood, J. Geophys. Res.-Atmos., 104, 19361-19366, https://doi.org/10.1029/1999JD900449, 1999.

Xia, Y., Mitchell, K., Ek, M., Cosgrove, B., Sheffield, J., Luo, L., Alonge, C., Wei, H., Meng, J., Livneh, B., Duan, Q., and Lohmann, D.: Continental-scale water and energy flux analysis and validation for North American Land Data Assimilation System project phase 2 (NLDAS-2): 2. Validation of model-simulated streamflow, J. Geophys. Res., 117, D03110, https://doi.org/10.1029/2011JD016051, 2012a.

Xia, Y., Mitchell, K., Ek, M., Sheffield, J., Cosgrove, B., Wood, E., Luo, L., Alonge, C., Wei, H., Meng, J., Livneh, B., Lettenmaier, D., Koren, V., Duan, Q., Mo, K., Fan, Y., and Mocko, D.: Continental-scale water and energy flux analysis and validation for the North American Land Data Assimilation System project phase 2 (NLDAS-2): 1 . Intercomparison and application of model products, J. Geophys. Res., 117, D03109, https://doi.org/10.1029/2011JD016048, 2012b.
Xia, Y., Mitchell, K., Ek, M., Sheffield, J., Cosgrove, B., Wood, E., Luo, L., Alonge, C., Wei, H., Meng, J., Livneh, B., Lettenmaier, D., Koren, V., Duan, Q., Mo, K., Fan, Y., and Mocko, D.: NLDAS Noah Land Surface Model L4 Hourly 0.125 x 0.125 degree V002, Greenbelt, Maryland, USA, Goddard Earth Sciences Data and Information Services Center (GES DISC), available at: https://doi.org/10.5067/47Z13FNQODKV (last access: April 2017), 2012c.

Xia, Y., Mitchell, K., Ek, M., Sheffield, J., Cosgrove, B., Wood, E., Luo, L., Alonge, C., Wei, H., Meng, J., Livneh, B., Lettenmaier, D., Koren, V., Duan, Q., Mo, K., Fan, Y., and Mocko, D.: NLDAS Primary Forcing Data L4 Hourly $0.125 \times 0.125$ degree V002, Greenbelt, Maryland, USA, Goddard Earth Sciences Data and Information Services Center (GES DISC), available at: https://doi.org/10.5067/6J5LHHOHZHN4 (last access: March 2017), 2012d.

Xia, Y., Ek, M. B., Wu, Y., Ford, T., and Quiring, S. M.: Comparison of NLDAS-2 Simulated and NASMD Observed Daily Soil Moisture. Part I: Comparison and Analysis, J. Hydrometeorol., 16, 1962-1980, https://doi.org/10.1175/JHM-D-14-0096.1, $2015 \mathrm{a}$.

Xia, Y., Ek, M. B., Wu, Y., Ford, T., and Quiring, S. M.: Comparison of NLDAS-2 Simulated and NASMD Observed Daily Soil Moisture. Part II: Impact of Soil Texture Classification and Vegetation Type Mismatches, J. Hydrometeorol., 16, 1981-2000, https://doi.org/10.1175/JHM-D-14-0097.1, 2015 b. 